\title{
Contraceptive failure in the United States
}

\author{
James Trussell, PhD \\ Office of Population Research, Princeton University, Princeton, NJ 08540, USA, The Hull York \\ Medical School, University of Hull, Hull HU6 7RX, England
}

\begin{abstract}
This review provides an update of previous estimates of first-year probabilities of contraceptive failure for all methods of contraception available in the United States. Estimates are provided of probabilities of failure during typical use (which includes both incorrect and inconsistent use) and during perfect use (correct and consistent use). The difference between these two probabilities reveals the consequences of imperfect use; it depends both on how unforgiving of imperfect use a method is and on how hard it is to use that method perfectly. These revisions reflect new research on contraceptive failure both during perfect use and during typical use.
\end{abstract}

\section{Keywords}

Contraceptive failure; Contraceptive efficacy

\section{Introduction}

Four pieces of information about contraceptive efficacy would help couples to make an informed decision when choosing a contraceptive method:

- Pregnancy rates during typical use show how effective the different methods are during actual use (including inconsistent or incorrect use).

- Pregnancy rates during perfect use show how effective methods can be, where perfect use is defined as following the directions for use.

- Pregnancy rates during imperfect use show how ineffective methods will be if they are used incorrectly or inconsistently. Pregnancy rates can be computed separately for different categories of imperfect use to reveal which types of imperfect use are most risky [1].

- The percentage of perfect users or percentage of months during which a method is used perfectly reveals how hard it is to use a method correctly and consistently.

The difference between pregnancy rates during imperfect use and pregnancy rates during perfect use reveals how forgiving of imperfect use a method is. The difference between pregnancy rates during typical use and pregnancy rates during perfect use reveals the consequences of imperfect use; this difference depends both on how unforgiving of imperfect use a method is and on how hard it is to use that method perfectly. Only the first

(C) 2013 Elsevier Inc. All rights reserved.

Publisher's Disclaimer: This is a PDF file of an unedited manuscript that has been accepted for publication. As a service to our customers we are providing this early version of the manuscript. The manuscript will undergo copyediting, typesetting, and review of the resulting proof before it is published in its final citable form. Please note that during the production process errors may be discovered which could affect the content, and all legal disclaimers that apply to the journal pertain. 
two pieces of information are currently available. Our current understanding of the literature on contraceptive efficacy is summarized in Table 1.

In the column 2 of Table 1, we provide estimates of the probabilities of pregnancy during the first year of typical use of each method in the United States. This information is shown graphically in Fig. 1 in a way that clients may find more useful [2]. For most methods, these estimates were derived from the experience of women in the 1995 National Survey of Family Growth (NSFG) [3] or the 1995 and 2002 NSFGs [3,4], so that the information pertains to nationally representative samples of users. For the other methods, we based the estimates on evidence from surveys and clinical investigations. Pregnancy rates during typical use reflect how effective methods are for the average person who does not always use methods correctly or consistently. Typical use does not imply that a contraceptive method was always used. In the NSFG and in most clinical trials, a woman is 'using' a contraceptive method if she considers herself to be using that method. So, typical use of the condom could include actually using a condom only occasionally, and a woman could report that she is 'using' the pill even though her supplies ran out several months ago. In short, 'use' - which is identical to 'typical use'-is a very elastic concept that depends entirely on an individual woman's perception.

In column 3 of Table 1, we provide our best guess of the probabilities of method failure (pregnancy) during the first year of perfect use. A method is used perfectly when it is used consistently according to a specified set of rules. For many methods, perfect use requires use at every act of intercourse. Virtually all method failure rates reported in the literature have been calculated incorrectly and are too low (see the discussion of methodological pitfalls below). Hence, we cannot empirically justify our estimates except those for four fertility awareness-based methods [1,5-7], the diaphragm [8], the sponge, [8] the male condom [911], the female condom [12], spermicides [13], and methods for which there are extensive clinical trials with very low pregnancy rates. Even the estimates for the fertility awarenessbased methods, female condom, diaphragm, spermicides, and sponge are based on only one or two studies. Our hope is that our understanding of efficacy during perfect use for these and other methods will be enhanced by additional studies.

Column 4 of Table 1 displays the first-year probabilities of continuing use. They are based on the same sources used to derive the estimates in the second column (typical use).

\section{No method}

Our estimate of the percentage of women becoming pregnant among those not using contraception is based on populations in which the use of contraception is rare, and on couples who report that they stopped using contraceptives because they want to conceive [14]. Based on this evidence, we conclude that 85 of 100 sexually active couples would experience a pregnancy in the first year if they used no contraception. Available evidence in the United States suggests that only about $40 \%$ of married couples who do not use contraception (but who still wish to avoid pregnancy) become pregnant within 1 year $[15,16]$. However, such couples are almost certainly selected for low fecundity or low frequency of intercourse. They do not use contraception because, in part, they are aware that they are unlikely to conceive. The probability of pregnancy of $85 \%$, therefore, is our best guess of the fraction of women now using reversible methods of contraception who would become pregnant within 1 year if they were to abandon their current method but not otherwise change their behavior. 


\section{Typical use of spermicides, withdrawal, fertility awareness-based methods, diaphragm, male condom, oral contraceptive pills, and Depo- Provera}

Our estimates of the probability of pregnancy during the first year of typical use for withdrawal, fertility awareness-based methods, the male condom, the pill, and Depo-Provera are taken from the 1995 and 2002 NSFG (the weighted average of the two estimates) and for spermicides and the diaphragm from the $1995 \mathrm{NSFG}$, all corrected for underreporting of abortion $[3,4]$.

The correction for underreporting of abortion may produce estimates that are too high because women in abortion clinics (surveys of whom provided the information for the correction) tend to overreport use of a contraceptive method at the time they became pregnant. Moreover, women in personal interviews for the NSFG also might overreport use of a contraceptive method at the time of a conception leading to a live birth. Evidence for this suspicion is provided by uncorrected first-year probabilities of pregnancy of $3.7 \%$ for intrauterine contraceptives and 2.3\% for Norplant (methods with little or no scope for user error) in the 1995 NSFG; these probabilities are much higher than rates observed in clinical trials of these methods [17]. We would naturally expect overreporting of contraceptive use in both the NSFG and surveys conducted in abortion clinics, because the woman (couple) can then blame the pregnancy on contraceptive "failure."

Thus, biases in opposite directions affect these estimates. Pregnancy rates based on the NSFG alone would tend to be too low because induced abortions (and contraceptive failures leading to induced abortions) are underreported but would tend to be too high because contraceptive failures leading to live births are overreported. We reason that the former bias is the more important one.

The NSFG does not ask for brand of pill; thus combined and progestin-only pills cannot be distinguished. However, since use of the combined pill is far more common than use of the progestin-only pill, the results from the NSFG overwhelmingly reflect typical use of combined pills. The efficacy of progestin-only pills may be lower than that for combined pills since progestin-only pills are probably less forgiving of nonadherence to the dosing schedule.

\section{Perfect use of the sponge and diaphragm}

Our estimates of the probabilities of pregnancy during the first year of perfect use of the sponge and diaphragm correspond with results of a reanalysis of data from two clinical trials in which women were randomly assigned to use the diaphragm or sponge or to use the diaphragm or cervical cap [8]. The results indicate that among parous women who use the sponge perfectly, $19.4 \%$ to $20.5 \%$ will experience a pregnancy within the first year. The corresponding range for nulliparous women is $9.0 \%$ to $9.5 \%$. In contrast, parous users of the diaphragm do not appear to have higher pregnancy rates during perfect use than do nulliparous users; $4.3 \%$ to $8.4 \%$ of all women experience an accidental pregnancy during the first year of perfect use of the diaphragm. Our estimates are obtained from the midpoints of these ranges.

\section{Typical use of the sponge}

Here we also draw on results of the same clinical trial in which women were randomly assigned to the sponge or diaphragm [18]. The proportion becoming pregnant during the first year of typical use for parous users of the sponge (27.4\%) was about twice as high as 
for nulliparous users of that method (14.0\%). There was no such differential for the diaphragm, where the proportion becoming pregnant in the first year of typical use for parous users (12.4\%) was marginally lower than that for nulliparous users (12.8\%) [18]. Therefore, we set the estimates for nulliparous users of the sponge equal to the estimate for all users of the diaphragm based on the 1995 NSFG (12\%) [3]. We doubled the estimates for nulliparous users of the sponge to obtain the estimate for parous users.

\section{Female condom}

The typical-use estimate for the female condom is based on the results of a 6-month clinical trial of the Reality female condom (now called the fc female condom); $12.4 \%$ of women in the United States experienced a pregnancy during the first 6 months of use [18]. The 12month probability of pregnancy for users of Reality in the United States was projected from the relation between the pregnancy rates in the first 6 months and the pregnancy rates in the second 6 months for users of the diaphragm, sponge and cervical cap [18]. The probability of pregnancy during 6 months of perfect use of Reality by U.S. women who met the adherence criteria stipulated in the study protocol was $2.6 \%$. Those who reported fewer than 4 acts of intercourse during the month prior to any follow-up visit, who did not use Reality at every act of intercourse, who ever reported not following the Reality instructions, or who used another method of contraception were censored at the beginning of the first interval where nonadherence was noted [19]. Under the assumption that the probability of pregnancy in the second 6 months of perfect use would be the same, the probability of pregnancy during a year of perfect use would be $5.1 \%$. There have been no efficacy trials of the second version of the female condom, the fc 2 female condom.

\section{Perfect use of withdrawal and spermicides}

Our estimate of the proportion of women becoming pregnant during a year of perfect use of withdrawal is a guess based on the reasoning that the risk of pregnancy resulting from preejaculatory fluid is modest. Although three studies found no motile sperm in the preejaculate [20-22], the most recent study did not replicate this result, perhaps because the samples were examined within 2 min of production [23]. In that study, 37\% of subjects produced pre-ejaculatory samples that contained motile sperm, and the sperm concentration and the percentage of motile sperm were similar in an individual's pre-ejaculatory and ejaculatory specimens. However, the actual number of sperm in the pre-ejaculate was low.

Our estimate of the proportion of women becoming pregnant during a year of perfect use of spermicides is based on a recent NIH trial of 5 spermicides [13]. We assumed that the pregnancy rate per cycle during perfect use would be constant, extrapolated a one-year probability from the 6-cycle probability reported for each method, and took as our estimate the median $(18 \%)$ of those 5 estimates.

\section{Perfect use of fertility awareness-based methods}

The perfect-use estimates for fertility awareness-based methods are based on empirical estimates of $4.8 \%$ for the Standard Days method [5], 3.5\% for the TwoDay method [6], $3.2 \%$ for the ovulation method [1], and 0.4 per 100 women-years for the symptothermal method [7]. Published "method failure" rates for other variants of natural family planning are incorrect, because exposure includes all use, not just perfect use [1].

\section{Perfect use of the male condom}

Our estimate of the proportion of women becoming pregnant during a year of perfect use of the male condom is based on results from the only three studies of the male condom meeting 
modern standards of design, execution, and analysis [9-11]. In each study, couples were randomly assigned to use either a latex condom or a polyurethane condom. All three studies reported efficacy during consistent use but only one reported efficacy during perfect use [10]; in that study the 6-cycle probability of pregnancy during perfect use $(0.7 \%)$ was $70 \%$ of that $(1 \%)$ during typical use. We assumed that in the other two studies the 6-cycle probability of pregnancy during perfect use would also be $70 \%$ of the 6 -cycle probability during typical use, assumed that the pregnancy rate per cycle during perfect use would be constant, extrapolated a one-year probability from the 6-cycle probability reported for the latex condom in each trial, and took as our estimate the median ( $2 \%$, also the mean) of those 3 estimates.

\section{Perfect use of oral contraceptive pills, Depo-Provera, and Implanon, and typical use of Implanon}

Although the lowest reported pregnancy rate for the combined pill during typical use is $0 \%$ [24-25], recent studies indicate that pregnancies do occur, albeit rarely, during perfect use $[26,27]$. Hence, we set the perfect-use estimate for the pill at the very low level of $0.3 \%$. The lowest reported pregnancy rate for the progestin-only pill exceeds $1 \%[28,29]$. It is likely that the progestin-only pill is less effective than the combined pill during typical use, since the progestin-only pill is probably less forgiving of nonadherence to the dosing schedule. Whether the progestin-only pill is also less effective during perfect use is unknown.

The perfect-use estimate for Depo-Provera is the weighted average of the results from seven trials of the $150 \mathrm{mg}$ IM dose (90-day or 3-month) and two trials of the $104 \mathrm{mg}$ SC dose [3037]. These trials yield an estimate of efficacy during perfect rather than typical use because either women late for an injection were discontinued or all pregnancies reported occurred during actual use (after one injection but before the next was scheduled). In the two trials of DMPA-SC, there were no reported pregnancies during perfect use. It is possible that DMPA-SC has higher efficacy than DMPA-IM during prefect use, but the company that markets both products has made no such claim.

Not one of 15 clinical studies has reported an Implanon failure [38-52]. However, pregnancies during use of Implanon have been reported [38]. We arbitrarily set the perfectuse and typical-use failure rates for Implanon at $0.05 \%$.

\section{Evra and NuvaRing}

The typical- and perfect-use estimates for the Evra patch and NuvaRing were set equal to those for the pill. It is possible that the patch and ring will prove to have better efficacy than the pill during typical use, because of better adherence with the dosing schedule. However, such superior efficacy has not been demonstrated in randomized trials. While in one trial the failure rate was lower among women randomly assigned to use the Evra patch (1.2\%) than among those assigned to use the pill (2.2\%), the difference was not statistically significant $(\mathrm{p}=0.6)$ [53]. In a subsequent paper that argues that better adherence to the dosing schedule leads to better contraceptive efficacy of the patch than the pill during typical use, the authors acknowledge that it would require a trial with 24,143 subjects to demonstrate such superiority and conclude that "studies of this size to compare effectiveness may not be practical" [54]. Women were randomly assigned to the NuvaRing or the pill in two studies. In one, the pregnancy rates were identical (1.2 per 100 women-years of exposure) [55]. In the second, the pregnancy rates did not differ significantly ( 0.25 versus 0.99 per 100 women-years of exposure) [56]. 


\section{Intrauterine contraceptives (IUCs)}

The estimate for typical use of the ParaGard (Copper T 380A) IUC, $0.8 \%$, is taken directly from the largest study for that method [57]. The estimate for Mirena (LNG-IUC), $0.2 \%$, is the weighted average of the results from three studies [58-60]. The estimate for perfect use of the Copper T 380A, $0.6 \%$, was obtained by removing the pregnancies that resulted when the device was not known to be in situ [61], on the perhaps-questionable assumption that these pregnancies should be classified as user failures and the empirically-based assumption that expulsions are so uncommon that the denominator of the perfect-use pregnancy rate is virtually the same as the denominator for the typical-use rate. The perfect-use estimate for the LNG-IUC, $0.2 \%$, was derived analogously. No differences in the typical-use and perfectuse estimates for LNG-IUC are apparent due to the fact that only one significant digit is shown.

\section{Sterilization}

The weighted average of the results from nine vasectomy studies analyzed with life-table procedures is $0.02 \%$ of women becoming pregnant in the year following the procedure [6270]. In eight of these studies, pregnancies occurred after the ejaculate had been declared to be sperm-free. This perfect-use estimate of $0.02 \%$ is undoubtedly too low, because clinicians are understandably loath to publish articles describing their surgical failures and journals would be reluctant to publish an article documenting poor surgical technique. The difference between typical-use and perfect-use pregnancy rates for vasectomy would depend on the frequency of unprotected intercourse after the procedure had been performed but before the ejaculate had been certified to be sperm-free. We arbitrarily set the typical- and perfect-use estimates to $0.15 \%$ and $0.10 \%$, respectively. For female sterilization (except for Essure or Adiana), there is no scope for user error. The typical- and perfect-use estimates are the pooled results from the U.S. Collaborative Review of Sterilization, a prospective study of 10,685 women undergoing tubal sterilization [71]. We are less concerned about publication bias with female than with male sterilization because the largest studies of female sterilization are based on prospective, multicenter clinical trials, not retrospective reports from one investigator.

\section{Contraceptive continuation}

Contraceptives will be effective at preventing unintended pregnancy only if women or couples continue to use. The proportions of women continuing use at the end of the first year for withdrawal, fertility awareness-based methods, the male condom, the pill, and DepoProvera were obtained from the 2002 NSFG and those for spermicides, the sponge, and the diaphragm were obtained from the 1995 NSFG $[16,17]$. Only method-related reasons for discontinuation (changing methods or termination of contraceptive use while still at risk for unintended pregnancy) were counted. Other reasons for discontinuing use of a method (such as attempting to get pregnant or not having intercourse) are not counted in the discontinuation rate because these reasons are unrelated to the method and do not apply to women seeking to avoid pregnancy and at risk of becoming pregnant. For the female condom, we adjusted the continuation rate for the male condom to reflect a higher pregnancy rate.

We set the continuation rates for the Evra patch and NuvaRing equal to that for the pill. We set the continuation rate for Implanon equal to that for Norplant, which was derived from the 1995 NSFG [17].

Discontinuation rates of the two IUCs (for reasons related to the contraceptive) are based on the same clinical trials that were used for the typical-use failure rates. 


\section{The Lactational Amenorrhea Method (LAM)}

LAM is a highly effective, temporary method of contraception. If the infant is being exclusively breastfed (or is given supplemental non-breastmilk or pumped breastmilk feeds only to a minor extent) and if the woman has not experienced her first postpartum menses, then breastfeeding provides more than $98 \%$ protection from pregnancy in the first 6 months following a birth [72,73]. Four prospective clinical studies of the contraceptive effect of LAM demonstrated cumulative 6-month life-table perfect-use pregnancy rates of $0.5 \%$, $0.6 \%, 1.0 \%$, and $1.5 \%$ among women who relied solely on LAM [74-77].

\section{Conclusion}

- Pregnancy rates during perfect use reflect how effective methods can be in preventing pregnancy when used consistently and correctly according to instructions.

- Pregnancy rates during typical use reflect how effective methods are for the average person who does not always use methods correctly or consistently.

- Pregnancy rates during typical use of adherence-dependent methods generally vary widely for different groups using the same method, primarily due to differences in the propensity to use the method perfectly.

- Additional empirically-based estimates of pregnancy rates during perfect use are needed.

\section{Acknowledgments}

This article is adapted from Trussell $\mathrm{J}$ and Guthrie $\mathrm{K}$, Choosing a Contraceptive: Safety, Efficacy, and Personal Considerations; and Trussell J, Contraceptive Efficacy. In: Hatcher RA, Trus-sell J, Nelson AL, Cates W, and Kowal D, editors. Contraceptive Technology: Twentieth Revised Edition. New York: Ardent Media, 2011, with the permission of Contraceptive Technology Communications, Inc.

\section{References}

1. Trussell J, Grummer-Strawn L. Contraceptive failure of the ovulation method of periodic abstinence. Fam Plann Perspect. 1990; 22:65-75. [PubMed: 2189750]

2. World Health Organization. Comparing typical effectiveness of contraceptive methods. Geneva: World Health Organization; 2007. [cited 2010 Jun 7]. Available from: http://www.fhi.org/nr/shared/ enFHI/Resources/EffectivenessChart.pdf

3. Trussell J. Estimates of contraceptive failure from the 1995 National Survey of Family Growth. Contraception. 2008; 78:85. [PubMed: 18555825]

4. Kost K, Singh S, Vaughan B, Trussell J, Bankole A. Estimates of contraceptive failure from the 2002 National Survey of Family Growth. Contraception. 2008; 77:10-21. [PubMed: 18082661]

5. Arévalo M, Jennings V, Sinai I. Efficacy of a new method of family planning: the Standard Days Method. Contraception. 2002; 65:333-8. [PubMed: 12057784]

6. Arévalo M, Jennings V, Nikula M, Sinai I. Efficacy of the new TwoDay Method of family planning. Fertil Steril. 2004; 82:885-92. [PubMed: 15482764]

7. Frank-Herrmann P, Heil J, Gnoth C, et al. The effectiveness of a fertility awareness based method to avoid pregnancy in relation to a couple's sexual behaviour during the fertile time: a prospective longitudinal study. Hum Reprod. 2007; 22:1310-9. [PubMed: 17314078]

8. Trussell J, Strickler J, Vaughan B. Contraceptive efficacy of the diaphragm, the sponge and the cervical cap. Fam Plann Perspect. 1993; 25:100-5. 135. [PubMed: 8354373]

9. Frezieres RG, Walsh TL, Nelson AL, Clark VA, Coulson AH. Evaluation of the efficacy of a polyurethane condom: results from a randomized controlled clinical trial. Fam Plann Perspect. 1999; 31:81-7. [PubMed: 10224546] 
10. Walsh TL, Frezieres RG, Peacock K, Nelson AL, Clark VA, Bernstein L. Evaluation of the efficacy of a nonlatex condom: results from a randomized, controlled clinical trial. Perspect Sex Reprod Health. 2003; 35:79-86. [PubMed: 12729137]

11. Steiner MJ, Dominik R, Rountree RW, Nanda K, Dorflinger LJ. Contraceptive effectiveness of a polyurethane condom and a latex condom: a randomized controlled trial. Obstet Gynecol. 2003; 101:539-47. [PubMed: 12636960]

12. Farr G, Gabelnick H, Sturgen K, Dorflinger L. Contraceptive efficacy and acceptability of the female condom. Am J Public Health. 1994; 84:1960-4. [PubMed: 7998637]

13. Raymond EG, Chen PL, Luoto J. Contraceptive effectiveness and safety of five nonoxynol-9 spermicides: a randomized trial. Obstet Gynecol. 2004; 103:430-9. [PubMed: 14990402]

14. Trussell, J. Contraceptive efficacy. In: Hatcher, RA.; Trussell, J.; Nelson, AL.; Cates, W.; Kowal, D., editors. Contraceptive Technology: Twentieth Revised Edition. New York: Ardent Media; 2011.

15. Grady WR, Hayward MD, Yagi J. Contraceptive failure in the United States: estimates from the 1982 National Survey of Family Growth. Fam Plann Perspect. 1986; 18:200-9. [PubMed: 3803556]

16. Vaughan B, Trussell J, Kost K, Singh, Jones R. Discontinuation and resumption of contraceptive use: Results from the 2002 National Survey of Family Growth. Contraception. 2008; 78:271-83. [PubMed: 18847574]

17. Trussell J, Vaughan B. Contraceptive failure, method-related discontinuation and resumption of use: results from the 1995 National Survey of Family Growth. Fam Plann Perspect. 1999; 31:6472. 93. [PubMed: 10224544]

18. Trussell J, Sturgen K, Strickler J, Dominik R. Comparative contraceptive efficacy of the female condom and other barrier methods. Fam Plann Perspect. 1994; 26:66-72. [PubMed: 8033980]

19. Farr G, Gabelnick H, Sturgen K, Dorflinger L. Contraceptive efficacy and acceptability of the female condom. Am J Public Health. 1994; 84:1960-4. [PubMed: 7998637]

20. Ilaria G, Jacobs JL, Polsky B, et al. Detection of HIV-1 DNA sequences in pre-ejaculatory fluid. Lancet. 1992; 340:1469. [PubMed: 1360583]

21. Pudney J, Oneta M, Mayer K, Seage G, Anderson D. Pre-ejaculatory fluid as potential vector for sexual transmission of HIV-1. Lancet. 1992; 340:1470. [PubMed: 1360584]

22. Zukerman Z, Weiss DB, Orvieto R. Does preejaculatory penile secretion originating from Cowper's gland contain sperm? J Assist Reprod Genet. 2003; 20:157-9. [PubMed: 12762415]

23. Killick SR, Leary C, Trussell J, Guthrie KA. Sperm content of pre-ejaculatory fluid. Hum Fertil. in press.

24. Preston SN. A report of a collaborative dose-response clinical study using decreasing doses of combination oral contraceptives. Contraception. 1972; 6:17-35. [PubMed: 4659582]

25. Ledger WJ. Ortho 1557-O: a new oral contraceptive. Int J Fertil. 1970; 15:88-92. [PubMed: 5430391]

26. Hernádi L, Marr J, Trummer D, De Leo V, Petraglia F. Efficacy and safety of a low-dose combined oral contraceptive containing drospirenone $3 \mathrm{mg}$ and ethinylestradiol $20 \mathrm{mcg}$ in a 24/4day regimen. Contraception. 2009; 80:18-24. [PubMed: 19501211]

27. Kroll R, Reape KZ, Margolis M. The efficacy and safety of a low-dose, 91-day, extended-regimen oral contraceptive with continuous ethinyl estradiol. Contraception. 2010; 81:41-48. [PubMed: 20004272]

28. Postlethwaite DL. Pregnancy rate of a progestogen oral contraceptive. Practitioner. 1979; 222:2725. [PubMed: 432188]

29. Shroff NE, Pearce MY, Stratford ME, Wilkinson PD. Clinical experience with ethynodiol diacetate $0.5 \mathrm{mg}$ daily as an oral contraceptive. Contraception. 1987; 35:121-34. [PubMed: 3297483]

30. Mishell DR, El-Habashy MA, Good RG, Moyer DL. Contraception with an injectable progestin. Am J Obstet Gynecol. 1968; 101:1046-53. [PubMed: 5663345]

31. World Health Organization. Multinational comparative clinical trial of long-acting injectable contraceptives: norethisterone enanthate given in two dosage regimens and depotmedroxyprogesterone acetate. Final report Contraception. 1983; 28:1-20. 
32. Schwallie PC, Assenzo JR. Contraceptive use-efficacy study utilizing medroxyprogesterone acetate administered as an intramuscular injection once every 90 days. Fertil Steril. 1973; 24:3319. [PubMed: 4698589]

33. Scutchfield FD, Long WN, Corey B, Tyler CW. Medroxyprogesterone acetate as an injectable female contraceptive. Contraception. 1971; 3:21-35.

34. Sangi-Haghpeykar H, Poindexter AN, Bateman L, Ditmore JR. Experiences of injectable contraceptive users in an urban setting. Obstet Gynecol. 1996; 88:227-33. [PubMed: 8692507]

35. World Health Organization. A multicentered Phase III comparative clinical trial of depotmedroxyprogesterone acetate given three-monthly at doses of $100 \mathrm{mg}$ or $150 \mathrm{mg}$ : I. Contraceptive efficacy and side effects. Contraception. 1986; 34:223-35. [PubMed: 2947777]

36. Jain J, Jakimiuk AJ, Bode FR, Ross D, Kaunitz AM. Contraceptive efficacy and safety of DMPASC. Contraception. 2004; 70:269-75. [PubMed: 15451329]

37. Kaunitz AM, Darney PD, Ross D, Wolter KD, Speroff L. Subcutaneous DMPA vs. intramuscular DMPA: a 2-year randomized study of contraceptive efficacy and bone mineral denisty. Contraception. 2009; 80:7-17. [PubMed: 19501210]

38. Graesslin O, Korver T. The contraceptive efficacy of Implanon: a review of clinical trials and marketing experience. Eur J Contracept Reprod Health Care. 2008; 13(Suppl 1):S4-12.

39. Zheng SR, Zheng HM, Qian SZ, Sang GW, Kaper RF. A randomized multicenter study comparing the efficacy and bleeding pattern of a single-rod (Implanon) and a six-capsule (Norplant) hormonal contraceptive implant. Contraception. 1999; 60:1-8. [PubMed: 10549446]

40. Zheng SR, Zheng HM, Qian SZ, Sang GW, Kaper RF. A long-term study of the efficacy and acceptability of a single-rod hormonal contraceptive implant (Implanon) in healthy women in China. Eur J Contracept Reprod Health Care. 1999; 4:85-93. [PubMed: 10427483]

41. Arribas-Mir L, Rueda-Lozano D, Agrela-Cardona M, Cedeno-Benavides T, Olvera-Porcel C, Bueno-Cavanillas A. Insertion and 3-year follow-up experience of 372 etonogestrel subdermal contraceptive implants by family physicians in Granada, Spain. Contraception. 2009; 80:457-62. [PubMed: 19835720]

42. Yildizbas B, Sahin HG, Kolusari A, Zeteroglu S, Kamaci M. Side effects and acceptability of Implanon: a pilot study conducted in eastern Turkey. Eur J Contracept Reprod Health Care. 2007; 12:248-52. [PubMed: 17763263]

43. Gezginc K, Balci O, Karatayli R, Colakoglu MC. Contraceptive efficacy and side effects of Implanon. Eur J Contracept Reprod Health Care. 2007; 12:362-5. [PubMed: 17853166]

44. Harvey C, Seib C, Lucke J. Continuation rates and reasons for removal among Implanon users accessing two family planning clinics in Queensland, Australia. Contraception. 2009; 80:527-32. [PubMed: 19913146]

45. Lakha F, Glasier AF. Continuation rates of Implanon in the UK: data from an observational study in a clinical setting. Contraception. 2006; 74:287-9. [PubMed: 16982226]

46. Thamkhantho M, Jivasak-Apimas S, Angsuwathana S, Chiravacharadej G, Intawong J. One-year assessment of women receiving subdermal contraceptive implant at Siriraj Family Planning Clinic. J Med Assoc Thai. 2008; 91:775-80. [PubMed: 18697372]

47. Agrawal A, Robinson C. An assessment of the first 3 years' use of Implanon in Luton. J Fam Plann Reprod Health Care. 2005; 31:310-2. [PubMed: 16274557]

48. Lipetz C, Phillips C, Fleming C. Actual cost of providing long-acting reversible contraception: a study of Implanon cost. J Fam Plann Reprod Health Care. 2009; 35:75-9. [PubMed: 19356275]

49. Rai K, Gupta S, Cotter S. Experience with Implanon in a northeast London family planning clinic. Eur J Contracept Reprod Health Care. 2004; 9:39-46. [PubMed: 15352694]

50. Booranabunyat S, Taneepanichskul S. Implanon use in Thai women above the age of 35 years. Contraception. 2004; 69:489-91. [PubMed: 15157794]

51. Flores JB, Balderas ML, Bonilla MC, Vazquez-Estrada L. Clinical experience and acceptability of the etonogestrel subdermal contraceptive implant. Int J Gynaecol Obstet. 2005; 90:228-33. [PubMed: 16043175]

52. Smith A, Reuter S. An assessment of the use of Implanon in three community services. J Fam Plann Reprod Health Care. 2002; 28:193-6. [PubMed: 12419059] 
53. Audet MC, Moreau M, Koltun WD, et al. Evaluation of contraceptive efficacy and cycle control of a transdermal contraceptive patch vs an oral contraceptive. JAMA. 2001; 285:2347-54. [PubMed: 11343482]

54. Archer DF, Cullins V, Creasy GW, Fisher AC. The impact of improved compliance with a weekly contraceptive transdermal system (Ortho Evra ${ }^{\circledR}$ ) on contraceptive efficacy. Contraception. 2004; 69:189-95. [PubMed: 14969665]

55. Oddsson K, Leifels-Fischer B, de Melo NR, et al. Efficacy and safety of a contraceptive vaginal ring (NuvaRing) compared with a combined oral contraceptive: a 1-year randomized trial. Contraception. 2005; 71:176-82. [PubMed: 15722066]

56. Ahrendt HJ, Nisand I, Bastianelli C, et al. Efficacy, acceptability and tolerability of the combined contraceptive ring, NuvaRing, compared with an oral contraceptive containing 30 microg of ethinyl estradiol and $3 \mathrm{mg}$ of drospirenone. Contraception. 2006; 74:451-7. [PubMed: 17157101]

57. Sivin I, Stern J. Long-acting, more effective copper T IUDs: a summary of U.S. experience, 19701975. Stud Fam Plann. 1979; 10:263-81. [PubMed: 516121]

58. Sivin I, El Mahgoub S, McCarthy T, et al. Long-term contraception with the Levonorgestrel 20 mcg/day (LNG-IUS) and the Copper T 380Ag intrauterine devices: a five-year randomized study. Contraception. 1990; 42:361-78. [PubMed: 2124179]

59. Luukkainen T, Allonen H, Haukkamaa M, et al. Effective contraception with the levonorgestrelreleasing intrauterine device: 12-month report of a European multicenter study. Contraception. 1987; 36:169-79. [PubMed: 3123132]

60. Cox M, Blacksell S. Clinical performance of the levonorgestrel intrauterine system in routine use by the UK Family Planning and Reproductive Health Research Network: 12-month report. Br J Fam Plann. 2000; 26:143-7. [PubMed: 10920290]

61. Sivin, I. Personal communication to James Trussell. Aug 13. 1992

62. Alderman PM. The lurking sperm: a review of failures in 8879 vasectomies performed by one physician. JAMA. 1988; 259:3142-4. [PubMed: 3367490]

63. Moss WM. A comparison of open-end versus closed-end vasectomies: a report on 6220 cases. Contraception. 1992; 46:521-5. [PubMed: 1493712]

64. Philp T, Guillebaud J, Budd D. Complications of vasectomy: review of 16,000 patients. Br J Urol. 1984; 56:745-8. [PubMed: 6534499]

65. Margaret Pyke Centre. One thousand vasectomies. Br Med J. 1973; 4:216-21. [PubMed: 4758395]

66. Kase S, Goldfarb M. Office vasectomy review of 500 cases. Urology. 1973; 1:60-2. [PubMed: 4792288]

67. Klapproth HJ, Young IS. Vasectomy, vas ligation and vas occlusion. Urology. 1973; 1:292-300. [PubMed: 4588625]

68. Schmidt SS. Vasectomy. JAMA. 1988; 259:3176. [PubMed: 3367495]

69. Marshall S, Lyon RP. Variability of sperm disappearance from the ejaculate after vasectomy. J Urol. 1972; 107:815-7. [PubMed: 5022549]

70. Jamieson DJ, Costello C, Trussell J, Hillis SD, Marchbanks PA, Peterson HB. US Collaborative Review of Sterilization Working Group. The risk of pregnancy after vasectomy. Obstet Gynecol. 2004; 103:848-50. Erratum in: Obstet Gynecol 2004;104:200. [PubMed: 15121555]

71. Peterson HB, Xia Z, Hughes JM, Wilcox LS, Tylor LR, Trussell J. The risk of pregnancy after tubal sterilization: findings from the U.S. Collaborative Review of Sterilization. Am J Obstet Gynecol. 1996; 174:1161-70. [PubMed: 8623843]

72. Kennedy KI, Rivera R, McNeilly AS. Consensus statement on the use of breastfeeding as a family planning method. Contraception. 1989; 39:477-96. [PubMed: 2656086]

73. Kennedy KI, Labbok MH, Van Look PFA. Lactational amenorrhea method for family planning. Int J Gynaecol Obstet. 1996; 54:55-7. [PubMed: 8842819]

74. Kazi A, Kennedy KI, Visness CM, Khan T. Effectiveness of the lactational amenorrhea method in Pakistan. Fertil Steril. 1995; 64:717-23. [PubMed: 7672141]

75. Labbok MH, Hight-Laukaran V, Peterson AE, Fletcher V, von Hertzen H, Van Look PFA. Multicenter study of the lactational amenorrhea method (LAM): I. Efficacy, duration, and implications for clinical application. Contraception. 1997; 55:327-36. [PubMed: 9262927] 
76. Pérez A, Labbok MH, Queenan JT. Clinical study of the lactational amenorrhoea method for family planning. Lancet. 1992; 339:968-70. [PubMed: 1348806]

77. Ramos R, Kennedy KI, Visness CM. Effectiveness of lactational amenorrhea in prevention of pregnancy in Manila, the Philippines: non-comparative prospective trial. Br Med J. 1996; 313:909-12. [PubMed: 8876092] 


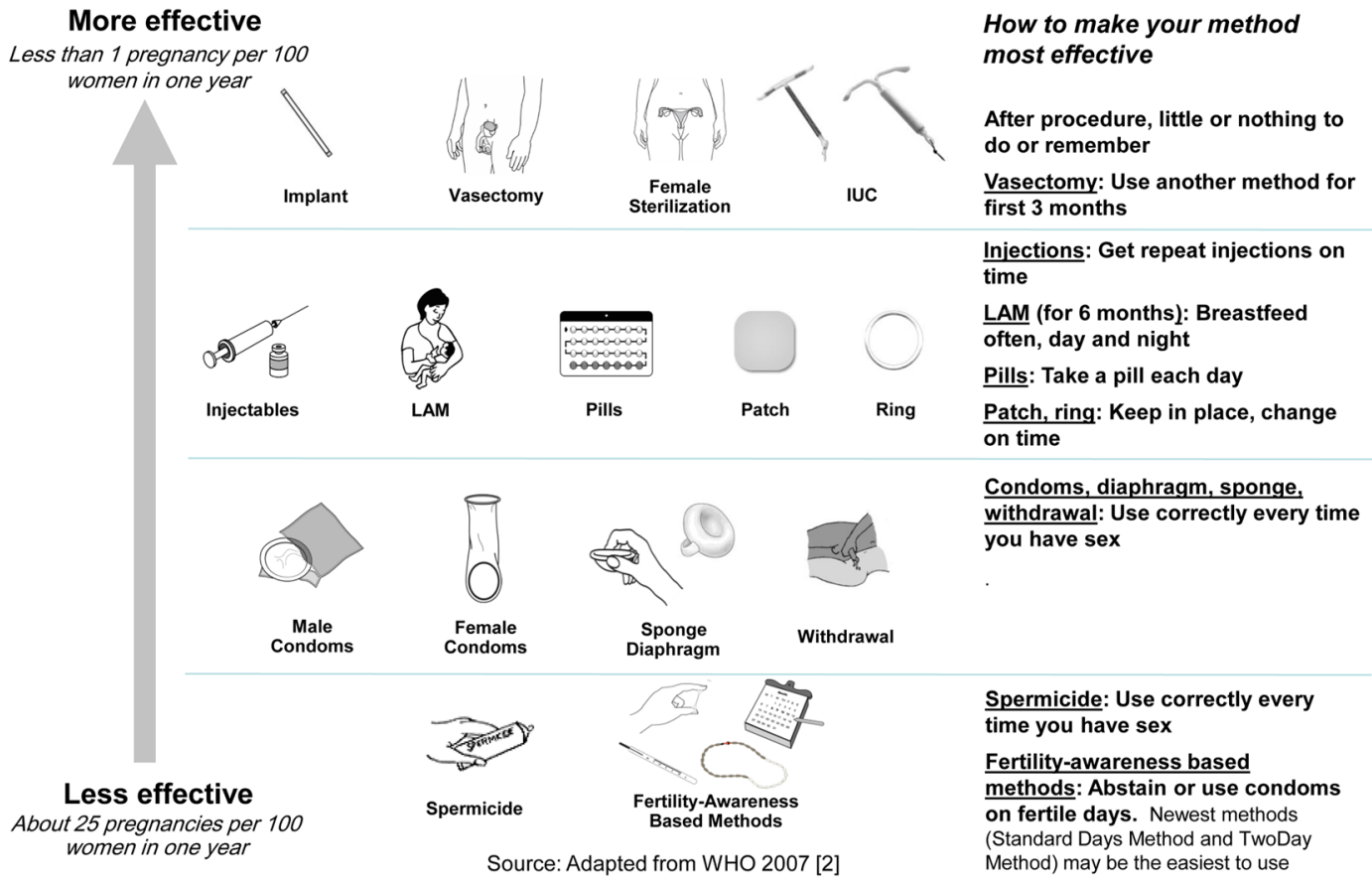

Fig. 1.

Comparing typical effectiveness of contraceptive methods 
Table 1

Percentage of women experiencing an unintended pregnancy during the first year of typical use and the first year of perfect use of contraception and the percentage continuing use at the end of the first year. United States.

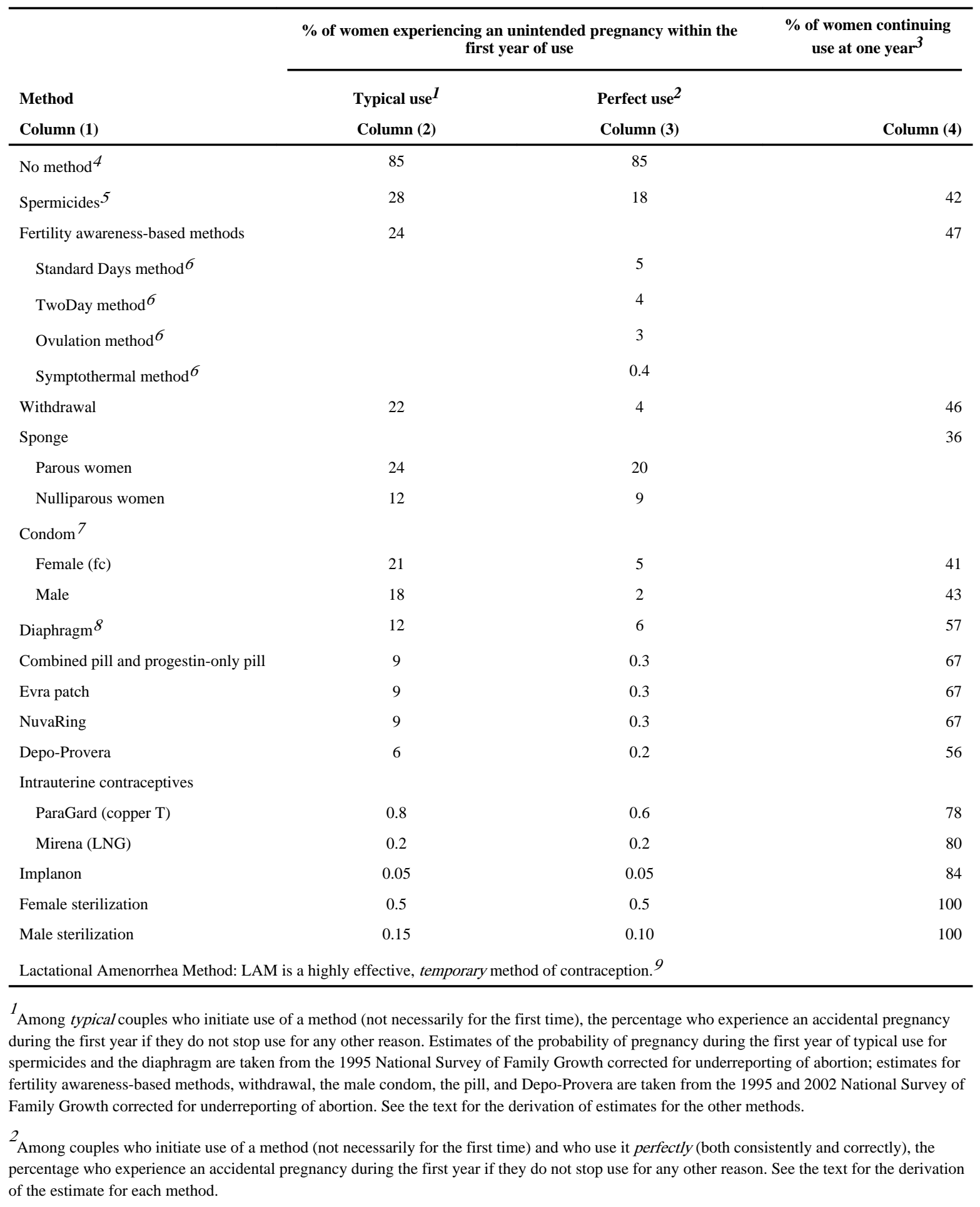


${ }^{3}$ Among couples attempting to avoid pregnancy, the percentage who continue to use a method for 1 year.

${ }^{4}$ The percentages becoming pregnant in columns (2) and (3) are based on data from populations where contraception is not used and from women who cease using contraception in order to become pregnant. Among such populations, about $89 \%$ become pregnant within 1 year. This estimate was lowered slightly (to $85 \%$ ) to represent the percentage who would become pregnant within 1 year among women now relying on reversible methods of contraception if they abandoned contraception altogether.

5 Foams, creams, gels, vaginal suppositories, and vaginal film.

6 Ovulation and TwoDay methods are based on evaluation of cervical mucus. The Standard Days method avoids intercourse on cycle days 8 through 19. The Symptothermal method is a double-check method based on evaluation of cervical mucus to determine the first fertile day and evaluation of cervical mucus and temperature to determine the last fertile day.

7 Without spermicides.

${ }^{8}$ With spermicidal cream or jelly.

9 However, to maintain effective protection against pregnancy, another method of contraception must be used as soon as menstruation resumes, the frequency or duration of breastfeeds is reduced, bottle feeds are introduced, or the baby reaches 6 months of age. 